\title{
Erratum zu „Frank Bösch. (2019). Zeitenwende 1979.““
}

\section{Anette Zimmer}

Online publiziert: 7. Juli 2021

(C) Der/die Autor(en) 2021

\section{Erratum zu:}

\section{Z Außen Sicherheitspolit 2020}

https://doi.org/10.1007/s12399-020-00796-8

Der Artikel „Frank Bösch. (2019). Zeitenwende 1979.“ von Anette Zimmer wurde ursprünglich am 19. Mai 2020 ohne „Open Access“ online auf der Internetplattform des Verlags publiziert. Die Autorin hat sich jedoch nachträglich für eine „Open Access"-Veröffentlichung entschieden. Das Urheberrecht des Artikels wurde deshalb 6. Juni 2021 in () The Author(s) 2020 geändert.

Weitere Details zur Lizenz entnehmen Sie bitte der Lizenzinformation auf http:// creativecommons.org/licenses/by/4.0/deed.de

Funding Open Access funding enabled and organized by Projekt DEAL

Open Access Dieser Artikel wird unter der Creative Commons Namensnennung 4.0 International Lizenz veröffentlicht, welche die Nutzung, Vervielfältigung, Bearbeitung, Verbreitung und Wiedergabe in jeglichem Medium und Format erlaubt, sofern Sie den/die ursprünglichen Autor(en) und die Quelle ordnungsgemäß nennen, einen Link zur Creative Commons Lizenz beifügen und angeben, ob Änderungen vorgenommen wurden.

Die in diesem Artikel enthaltenen Bilder und sonstiges Drittmaterial unterliegen ebenfalls der genannten Creative Commons Lizenz, sofern sich aus der Abbildungslegende nichts anderes ergibt. Sofern das betreffende Material nicht unter der genannten Creative Commons Lizenz steht und die betreffende Handlung nicht nach gesetzlichen Vorschriften erlaubt ist, ist für die oben aufgeführten Weiterverwendungen des Materials die Einwilligung des jeweiligen Rechteinhabers einzuholen.

Die Online-Version des Originalartikels ist unter https://doi.org/10.1007/s12399-020-00796-8 zu finden.

Prof. Dr. Anette Zimmer ( $\bowtie)$

Institut für Politikwissenschaft, Westfälische Wilhelms-Universität Münster,

Scharnhorststr. 100, 48151 Münster, Deutschland

E-Mail: zimmean@uni-muenster.de 
Weitere Details zur Lizenz entnehmen Sie bitte der Lizenzinformation auf http://creativecommons.org/ licenses/by/4.0/deed.de. 